Bryn Mawr College

Scholarship, Research, and Creative Work at Bryn Mawr

College

Psychology Faculty Research and Scholarship

Psychology

2017

\title{
American Undergraduate Students' Value Development During the Great Recession
}

Heejung Park

Bryn Mawr College, hpark2@brynmawr.edu

Jean $\mathrm{M}$. Twenge

Patricia M. Greenfield

Let us know how access to this document benefits you.

Follow this and additional works at: http://repository.brynmawr.edu/psych_pubs

Part of the Psychology Commons

\section{Custom Citation}

Park, Heejung, Twenge, Jean M., and Greenfield, Patricia M. 2017. American undergraduate students' value development during the Great Recession. International Journal of Psychology 52.1:28-39.

This paper is posted at Scholarship, Research, and Creative Work at Bryn Mawr College. http://repository.brynmawr.edu/psych_pubs/59

For more information, please contact repository@brynmawr.edu. 
American Undergraduate Students' Value Development during the Great Recession

\author{
Heejung Park ${ }^{1}$ \\ Jean M. Twenge ${ }^{2}$ \\ Patricia M. Greenfield ${ }^{3}$
}

${ }^{1}$ Department of Psychology, Bryn Mawr College, ${ }^{2}$ Department of Psychology, San Diego State University, ${ }^{3}$ Department of Psychology, UCLA Address correspondence to Heejung Park, Ph.D., Department of Psychology, Bryn Mawr College, 101 N. Merion Avenue, Bryn Mawr, PA 19010. E-mail: hpark2@brynmawr.edu Acknowledgments: We would like to acknowledge the important role of John Pryor, the Director of the Cooperative Institutional Research Program at the UCLA Higher Education Research Institute (HERI), who organized the initial database for us. We also thank Mark Leung for administering our grant. We dedicate this article to the memory of Professor Helen S. Astin (1932-2015), Senior Scholar in the HERI, and pioneer in the study of college and university students' search for life meaning. Along with Professor Alexander Astin, founder of the Freshman and Senior Surveys, and Professor Sylvia Hurtado, then Director of HERI, she facilitated access to the data archive used in this paper. We thank the Russell Sage Foundation for the grant that supported this research. 
Running head: THE GREAT RECESSION AND YOUTH VALUES

\begin{abstract}
The Great Recession's influence on American undergraduate students' values was examined, testing Greenfield's and Kasser's theories concerning value development during economic downturns. Study 1 utilized aggregate-level data to investigate 1) population-level value changes between the prerecession (2004-06: $n=824,603)$ and recession freshman cohort (2008-10: $n=$ 662,262 ) and 2) overall associations of population-level values with national economic climates over long-term periods by correlating unemployment rates and concurrent aggregate-level values across 1966-2015 ( $n=10$ million). Study 2 examined individual-level longitudinal value development from freshman to senior year, and whether the developmental trajectories differed between those who completed undergraduate education before the Great Recession (freshmen in $2002, n=12,792)$ vs. those who encountered the Great Recession during undergraduate years (freshmen in 2006, $n=13,358$ ). Results suggest American undergraduate students' increased communitarianism (supporting Greenfield) and materialism (supporting Kasser) during the Great Recession. The recession also appears to have slowed university students' development of positive self-views. Results contribute to the limited literature on the Great Recession's influence on young people's values. They also offer theoretical and practical implications, as values of this privileged group of young adults are important shapers of societal values, decisions, and policies.
\end{abstract} Keywords: Great Recession, values, youth, birth cohort, longitudinal 
American Undergraduate Students' Value Development during the Great Recession

The current generation of American young adults spent their childhoods in national economic plenty and their young adulthoods in the Great Recession, one of the worst recessions in the history of the United States, officially lasting 2007-2009 (Grusky, Western, \& Wimer, 2011). Economic times constitute environments that foster certain values, and competing theories posit how economic downturns alter value development. Greenfield (2009) contends that less wealth fosters collectivism and dampens individualism; Kasser (2002a) asserts that less wealth promotes extrinsic values (e.g., materialism) and reduces intrinsic values (e.g., community feelings and positive self-expression). Testing the two theories, we investigated how the Great Recession influenced values of students who experienced the recession during their formative years of young adulthood.

\section{Values of Undergraduate Students}

Value change is an important consequence of recessions given that values guide goals and behavior (Schwartz, 1994) and influence wellbeing (Kasser, 2002b). Furthermore, individuals' values as a collective constitute population-level societal values (Markus \& Kitayama, 2010). Thus, the Great Recession's influence on values has significance not only for directing personal lives but also for shaping societal ideologies, norms, and actions of the current and future generations.

Undergraduate students attending four-year colleges and universities are considered a privileged group of young adults, bolstering the importance of examining their values as a catalyst for shaping American culture. Given their privileged status, some may posit that these students are shielded from recessions' effects. However, events that are radically discrepant from prior experiences have a larger developmental impact than events that can be more easily 
assimilated into prior experience (Stewart \& Healy, 1989). The Great Recession might have been a more discrepant, thus more impactful, event for young adults who afforded undergraduate education than for their peers who entered workforce after high school. Additionally, the educational cost and decision-making process may expose students to their financial circumstances, sensitizing them to the recession's effects. Therefore, a focus on undergraduate students' value change during the Great Recession is a meaningful way to understand how the recent economic downturn has influenced young adults' values.

Developmentally, young adulthood is an important period as social changes have the strongest effects during the transition to adulthood (Stewart \& Healy, 1989). Young adults are still malleable and sensitive to environmental changes as they continue cognitive, biological, and social maturation in adolescence. Yet compared with high school years, young adults in undergraduate institutions engage in more active self-exploration and become more aware of the outside world (Arnett, 2004). Supporting the notion that young adulthood is a sensitive period for responding to societal economic downturns, experiencing recessions was associated with people's attitudes only for those who experienced recessions when they were 18-25 years, but not before 18 or after 25 (Giuliano \& Spilimbergo, 2014). In short, undergraduate students' increased pursuit of independence, self-exploration, and societal awareness may lead to reexamination and reconstruction of their values, a process influenced by events such as the Great Recession.

\section{Competing Theories Predicting the Great Recession's Influence on Values}

While values may be conceptualized in various ways, we focused on communitarianism, positive self-views, and materialism, based on Greenfield's and Kasser's theories that provided competing hypotheses. 
Greenfield's Theory of Social Change and Human Development. Greenfield (2009) posits that less wealth fosters collectivism and dampens individualism through a process of human adaptation to social conditions. Communitarianism is an aspect of collectivism, which highlights one's obligation and responsibility towards others and groups (Markus \& Kitayama, 2010). Conversely, positive self-views are valued in individualistic cultures much more than in collectivistic cultures, as they help to maintain one's positive self-regard and protect self-esteem (Heine, Lehman, Markus, \& Kitayama, 1999). With its emphasis on wealth and property, materialism is another correlate of individualism (Vohs, Mead \& Goode, 2006).

Greenfield (2009) explains that collectivism is adaptive in poorer, rural, small-scale environments with subsistence-based economy, low-education, and simple technology, termed as Gemeinschaft (Tönnies, 1957) where people form lifelong relations and engage in constant faceto-face interactions. Conversely, individualism is adaptive in wealthier, urban, large-scale environments, termed as Gesellschaft (Tönnies, 1957); people have frequent fleeting interactions with strangers. Viewing Gemeinschaft and Gesellschaft as prototypes on a continuum, Greenfield contends that global social conditions moving from relatively Gemeinschaft to Gesellschaft environments have changed people's values towards less collectivism and more individualism. The theory predicts that values would become more collectivistic and less individualistic when aspects of social conditions reverse such as the case of recessions.

Kasser's Self-Determination Theory of Values. Kasser (2002a) asserts that less wealth causes people to shift from intrinsic to extrinsic values. He considers community feelings and positive self-expression as intrinsic values, and materialism as a type of extrinsic values. Kasser reasons that economic hardships threaten people's sense of control and feelings of security, hampering people from feeling close to others (communitarianism) and viewing and expressing 
themselves positively (positive self-views). As a compensatory strategy, people focus on extrinsic values (materialism) that may appear to promise security in situations of uncertainty and insecurity.

Communitarianism. Thus, Greenfield's theory would predict increased communitarianism while Kasser's theory would predict reduced communitarianism during the Great Recession. Emerging research suggests that recessions may strengthen communitarianism among young people, favoring Greenfield's theory. For instance, analyzing data from 1972 to 2006, Giuliano and Spilimbergo (2014) found that Americans who experienced recessions as young adults were more likely to endorse the importance of helping poor and reducing income inequality, compared with those who did not encounter recessions as young adults. However, the timespan in the study was prior to the Great Recession. Additionally, the study focused on analyzing the general association of values with national economic indicators across an extended timespan, rather than focused on one particular recession period. It is important to understand how values shifted during the Great Recession specifically in the context of overall historical associations of national economic indicators with values, given that young people's value development in recent generations have been impacted by unique societal factors such as the Internet (e.g., Gentile, Twenge, Freeman, \& Campbell, 2012).

Focusing on the Great Recession, Park, Twenge, and Greenfield (2014) found that American high school seniors in the Great Recession years (2008-10) had higher concern for others and community compared with peers in the immediately preceding years (2004-06). They also found robust correlations between the communitarian values and indicators of recessions across 1976-2010, suggesting similar influences of the Great Recession and recessions in general on high school students' communitarianism. Yet it remains unclear whether young adults, 
particularly a privileged group of undergraduate students, would mirror the findings.

Positive self-views. Both Greenfield's and Kasser's theories predict positive self-views to decline during the Great Recession. Indeed, some studies have shown that development of positive self-views is less likely if young people experience recessions. Using unemployment rates as an indicator of recession, Bianchi (2014) found that experiencing recessions in young adulthood weakened development of unrealistically positive self-views. Similarly, Park et al. (2014) found that high school seniors' beliefs that they were better than average on intelligence and school ability were lower during less affluent times across 1976-2010; the above-average phenomenon is a robust measurement of positive self-views and a correlate of individualism (Heine et al., 1999).

Nonetheless, when focusing on the Great Recession, high school seniors' above-average ratings actually increased between 2004-06 and 2008-10 periods (Park et al., 2014), questioning whether past recessions and the Great Recession had similar influences on young people's positive self-views. Given that positive self-views have been rising over generations (Twenge \& Campbell, 2008), more research is needed to clarify whether the recent economic downturn has been an impactful event that altered the valence of young people's self-views.

Materialism. Greenfield's theory predicts dampened materialism, while Kasser's theory predicts increased materialism, during the Great Recession. Supporting Greenfield's theory, Bianchi (2014) found that company executives who experienced recessions when they were 1825 years paid themselves relatively less than peers who were 18-25 years during economically prosperous times. Park et al. (2014) found that high school seniors of the Great Recession were less likely to value the importance of owning expensive items than those in the immediately preceding years. At the individual socioeconomic level, experimental studies showed that lower- 
income participants were more charitable than those with greater wealth (Piff, Kraus, Cheng, \& Keltner, 2010).

Supporting Kasser's theory, teenagers who grew up in socioeconomically disadvantageous environments had greater materialism and mothers who emphasized their financial success (Kasser, Ryan, Zax, \& Sameroff, 1995). The results were interpreted as extrinsic values such as materialistic gains and security having a greater meaning than intrinsic values for individuals in low-socioeconomic environments. Given the mixed findings, clarifying the link between poor economic conditions and materialism addresses a gap in the literature. This investigation also has important developmental implications given that materialism is associated with poor wellbeing among young people (Kasser, 2002b).

\section{The Present Research}

In two studies, we investigated how the Great Recession influenced American undergraduate students' values. Study 1 utilized aggregate-level data to investigate 1) short-term population-level value changes during the Great Recession by comparing the prerecession (200406: $n=824,603)$ and recession freshman cohort $(2008-10: n=662,262)$ and 2$)$ overall associations of population-level values with national economic climates over long-term periods by correlating unemployment rates and concurrent aggregate-level values across all years surveyed (1966-2015, $n=10$ million). Key strengths of Study 1 included large sample sizes and an attention to both the Great Recession and overall recessions as shapers of values.

Study 2 moved from aggregate-level analyses of 50 years of data to individual-level analyses of two longitudinal cohorts of students who completed surveys in both their freshman and senior year. The prerecession longitudinal cohort began and finished undergraduate education immediately before the Great Recession, serving as a benchmark for identifying 
normative patterns of value development during undergraduate years. More specifically, commonalities between this prerecession cohort and the recession cohort who experienced the Great Recession in the middle of their undergraduate years would suggest students' normative value development. In contrast, differences between the two longitudinal cohorts would reveal how the experience of a sharp economic downturn may have altered the normative trajectory of value development. To our knowledge, this was the first study to trace longitudinal value changes of young people who experienced the Great Recession, as well as comparing the longitudinal changes with the developmental pattern of an immediately preceding prerecession cohort. This approach recognizes that values develop and change through undergraduate years (Sheldon, 2005), contextualizing the Great Recession's influence on values in a developmental framework. Additionally, we explored whether individual-level SES, indexed by first-generation student status, modified the influence of the Great Recession on students' longitudinal value trajectories.

In summary, Study 1 connected national economic trends with population-level societal values, both over a long timespan of 50 years and a short timespan that focused on the Great Recession. Study 2 investigated individual-level longitudinal value development trajectories before and during the Great Recession. Together, the two studies shed light onto understanding how macro economic downturns may operate at population- and individual-levels to shape values.

\section{Study 1}

Utilizing publically available aggregate-level data, we compared population-level values of freshmen between the prerecession (2004-06) and recession (2008-10) period. Furthermore, we extended the relationship between economic times and values by examining the correlation of 
values with unemployment rates, indicating poor economic times, across all survey years (19662015). The following hypotheses were tested:

Hypothesis 1a: Communitarianism would be stronger (Greenfield, 2009) or weaker (Kasser, 2002a) in the Great Recession period than in the immediate prerecession period.

Hypothesis 1b: Over the long-term (1966-2015), higher unemployment rates would be associated with stronger (Greenfield, 2009) or weaker (Kasser, 2002a) communitarianism.

Hypothesis 2a: Positive self-views would be lower in the Great Recession period than in the immediate prerecession period (Greenfield, 2009; Kasser, 2002a).

Hypothesis 2b: Over the long-term (1966-2015), higher unemployment rates would be associated with lower positive self-views (Greenfield, 2009; Kasser, 2002a).

Hypothesis 3a: Materialism would be lower (Greenfield, 2009) or higher (Kasser, 2002a) in the Great Recession period than in the immediate prerecession period.

Hypothesis 3b: Over the long term (1966-2015), higher unemployment rates would be associated with lower (Greenfield, 2009) or higher (Kasser, 2002a) materialism.

\section{Method}

\section{Participants}

Data came from the Freshman Survey directed by the Higher Education Research Institute (HERI). Since 1966, hundreds of U.S. colleges and universities have administered the survey to entering students during orientation or registration annually. HERI annually publishes the data, at the aggregate level by year. Thus, the resulting data provide information on national samples of American undergraduate students in over the past half-century. We limited our study to students in four-year institutions to have a comparable population to Study 2, where we assessed longitudinal value development over the four years of undergraduate education. 
Study 1 participants were freshmen from 1966 to 2015, wherein 2004-06 represented the prerecession period, and 2008-10 the Great Recession period. Three years captured a representative sample of participants in each period and minimized error variance; 2007 was excluded, considered as a transitional year (Park et al., 2014). Indeed, unemployment was low in the three years immediately preceding the recession $(2004-06, M=5.1 \%)$ but rose during the recession (2008-10, $M=8.2 \%)$. The sample size (1966-2015) was approximately 10 million (2004-06: $n=824,603 ; 2008-10: n=662,262$ on most items).

\section{Measures}

In publishing data, HERI dichotomized the item scales and reported the percentages of those who chose higher scale points indicating the endorsement of each item; our measures and analyses followed the way that data were reported in the available HERI publications. HERI also weighted the data to be representative of all students entering four-year undergraduate institutions. For each variable, yearly aggregate measures from 1966 to 2015 were used for the long-term analyses. To compare the three-year prerecession cohort with the three-year recession cohort, aggregate measures for those particular years were used in the analyses.

Communitarianism. Communitarianism was examined in participants' response to questions asking about the personal importance of "helping others who are in difficulty", "participating in a community action program", and "becoming involved in programs to clean up the environment" $(1=$ not important, $2=$ somewhat important, $3=$ very important, $4=$ essential $)$. Data were available as the percentage who chose "very important" or "essential."

Positive self-views. Participants responded to "Rate yourself on each of the following traits, as compared with the average person your age. We want the most accurate estimate of how you see yourself." The traits were "self-confidence (social)" and "self-confidence (intellectual)." 
$(1=$ lowest $10 \%, 2=$ below average, $3=$ average, $4=$ above average, $5=$ highest $10 \%)$. Data were available as the percentage who chose "above average" or "highest $10 \%$ ".

Materialism. Participants indicated the personal importance of "being very well off financially" $(1=$ not important, $2=$ somewhat important, $3=$ very important, $4=$ essential $)$. Data were available as the percentage who chose "very important" or "essential."

Unemployment rates. For the long-term analyses, contemporaneous yearly unemployment rates were obtained 1966-2015, using the U.S. Census Bureau website information.

\section{Data Analysis Strategy}

Prerecession (2004-06) vs. recession (2008-10). To examine short-term changes in values during the Great Recession, we compared the responses of freshmen in the prerecession (2004-06) vs. recession (2008-10) period. This approach of examining the responses of different participants of a similar age group at different time periods is known as a time-lag design (e.g., Twenge, 2010). We examined the significance $(p)$ and effect sizes $(d)$ to interpret the findings. In population-based studies, small effect sizes have theoretical and practical meanings and confirm population-level changes. Even relatively small mean differences produce large changes at the ends of the distribution and suggest a considerable potential impact on society (Twenge \& Campbell, 2010).

Association with unemployment rates. To examine long-term overall associations of recessions with population-level values, we ran correlation analyses between each value item and the unemployment rate by year across all available years of the Freshman Survey data (19662015). Correlations were weighted for sample size, and the number of years minus two was the 
degrees of freedom. The number of years slightly varied across the items because items varied in years when they were administered.

\section{Results}

Results are shown in Table 1, along with the percentages of freshmen in the prerecession and recession period who endorsed items tapping communitarianism, positive self-views, and materialism.

\section{Communitarianism}

Hypothesis 1a. Supporting Greenfield's theory, the importance of all three items tapping communitarianism was higher in the Great Recession period than in the immediately preceding prerecession period. Effect sizes suggested the greatest increase in the importance of cleaning up

the environment $(d=.19)$, followed by community action programs $(d=.12)$, then helping others $(d=.09)$.

Hypothesis 1b. Over the long-term (1966-2015), the importance of helping others was correlated with higher unemployment rates, also supporting Greenfield's theory. However, correlations with unemployment rates were non-significant for the importance of community action programs and cleaning up the environment.

\section{Positive Self-Views}

Hypothesis 2a. Positive self-views, measured by above-average self-ratings, indicated a small decline in social-confidence during the Great Recession, supporting Greenfield's and Kasser's theories. However, intellectual confidence was not different between the prerecession and recession period.

Hypothesis 2b. Over the long-term (1966-2015), positive self-views were not correlated with unemployment rates, providing no support for either theory. 


\section{Materialism}

Hypothesis 3a. Materialism, measured as valuation of the importance of being very welloff financially, was higher during the Great Recession compared with the immediate prerecession period, supporting Kasser's theory.

Hypothesis 3b. Over the long term (1966-2015), materialism was correlated with higher unemployment rates 1966-2015, supporting Kasser's theory.

\section{Study 2}

Study 2 focused on individual-level value development and examined whether the Great Recession influenced longitudinal trajectories of value development during undergraduate years. Specifically, it compared students who began and completed undergraduate education a year before the Great Recession officially began (freshmen in 2002) with those who began education before the recession but encountered the recession in the middle of their undergraduate years (freshmen in 2006). These were longitudinal four-year cohorts whose time windows were not the same as the cross-sectional cohorts in Study 1; the longitudinal prerecession cohort in Study 2 was not part of Study 1, and the longitudinal recession cohort in Study 2 was part of the prerecession freshman cohort in Study 1. Given that the longitudinal recession cohort in Study 2 began undergraduate education before the Great Recession started, group-mean comparisons of freshman values between the prerecession and recession cohort was irrelevant in Study 2. Instead, Study 2 analyses focused on the value change from freshman to senior year as a function of experiencing the Great Recession, accounting for different starting means for the prerecession and recession cohort in freshman year.

As with Study 1, Greenfield's and Kasser's theories provided hypotheses concerning the Great Recession's influences on value development. Furthermore, Sheldon's (2005) longitudinal 
study, which showed stability in communitarianism, increases in intrinsic values tapping positive self-views, and declines in materialism from freshman to senior year, informed our hypotheses concerning normative value development during undergraduate years:

Hypothesis 1a: For the prerecession cohort (representing normative value development during undergraduate years), there would be little change in communitarianism from freshman to senior year (Sheldon, 2005).

Hypothesis 1b: For the recession cohort, communitarianism would increase (Greenfield, 2009) or decline (Kasser, 2002a) from freshman to senior year.

Hypothesis 2a: For the prerecession cohort (representing normative value development), there would be increasingly positive self-views from freshman to senior year (Sheldon, 2005).

Hypothesis 2b: For the recession cohort, positive self-views would stabilize or decline from freshman to senior year (Greenfield, 2009; Kasser, 2002a).

Hypothesis 3a: For the prerecession cohort (representing normative value development), there would be declines in materialism from freshman to senior year (Sheldon, 2005).

Hypothesis 3b: For the recession cohort, materialism would decline from freshman to senior year at a greater rate than for the prerecession cohort (Greenfield, 2009). Alternatively, materialism would decline at a slower rate or increase for the recession cohort compared with the prerecession cohort (Kasser, 2002a).

Finally, we explored whether individual-level SES, indexed by first-generation student status, modified the influence of the Great Recession on students' longitudinal value trajectories. To our knowledge, this was the first study to examine whether individual-level SES (i.e., firstgeneration status) would modify the degree to which population-level SES (i.e., recession) 
influences value development (i.e., value change from freshman to senior year). Specific hypotheses were not generated given the exploratory nature of this question.

\section{Method}

\section{Participants}

Participants were two cohorts of undergraduate students who took both the HERI Freshman Survey (TFS) and College Senior Survey (CSS). The prerecession cohort participants were freshmen in 2002 and seniors in 2006; they began and completed undergraduate education before the recession officially began in 2007 . The recession cohort participants were freshmen in 2006 and seniors in 2010; the recession occurred in the middle of their undergraduate years. The sample size was 26,150 (prerecession cohort: $n=12,792, M_{\text {age }}=18.29, S D=.51,65 \%$ female; recession cohort: $n=13,358, M_{\text {age }}=18.29, S D=50,63 \%$ female).

\section{Measures}

Communitarianism, positive self-views, and materialism. The same items in Study 1 were examined in Study 2 to assess communitarianism, positive self-views, and materialism. For Study 2, full-scale individual data were obtained. Table 2 shows the range, mean, and standard deviation of each item by year and cohort.

Year. We structured the dataset to represent the repeated measurements of participants' values in their freshman and senior year, represented as the variable, year $(1=$ freshman year, 2 $=$ senior year $)$.

Cohort. Cohort represented whether or not participants experienced the Great Recession during their undergraduate years $(0=$ prerecession cohort, $1=$ recession cohort $)$.

First-generation status. First-generation student status was assessed based on the information participants provided about their parents' education levels. Consistent with prior 
research (e.g., Stephens et al., 2012), participants were classified as first generation if they indicated that neither parent had an undergraduate degree. $26 \%$ of the prerecession cohort and $22 \%$ of the recession cohort participants were first generation.

\section{Data Analysis Strategy}

In multiple regression models predicting students' values, we examined the main effect of year to examine change from freshman to senior year, and the interactive effect of year with cohort to test whether value change from freshman to senior year differed between prerecession vs. recession cohort. We also tested three-way interactions of year, cohort, and first-generation status to explore whether differential value changes from freshman to senior year between prerecession vs. recession cohort was further moderated by first-generation vs. continuinggeneration student status. Significant interactions were followed by simple slope tests and pairwise comparisons of the slopes. For comprehensiveness, the models also included main effects of cohort and first-generation status, interactive effects of first-generation status with cohort and year, and control variables of age and sex. Inclusion of the additional variables did not change the results for our main analyses.

\section{Results}

\section{Communitarianism}

Contrary to Sheldon's (2005) prior research that showed stability in communitarianism, we found that valuation of all three items assessing communitarianism increased from freshman to senior year for both prerecession and recession cohorts, suggesting normative increases in communitarianism during university years (Table 2 and 3, Figure 1).

Furthermore, pairwise comparisons of the simple slopes for prerecession vs. recession cohorts revealed that the upward developmental trajectories of two indicators, importance of 
community action program and cleaning up the environment, significantly differed between the two cohorts $(p<.001)$. Favoring Greenfield's theory, the magnitude of increase was significantly larger for the recession cohort compared with the prerecession cohort.

\section{Positive Self-Views}

Social self-confidence and intellectual self-confidence ratings increased from freshman to senior year for both prerecession and recession cohort, suggesting normative rises in positive self-views during undergraduate years and bolstering Sheldon's prior findings (Table 2 and 3 , Figure 2).

Pairwise comparisons revealed that the upward developmental trajectories of the two cohorts were significantly different from each other. The developmental increase in positive selfviews was significantly smaller for the recession cohort compared with the prerecession cohort, for both social $(p<.001)$ and intellectual $(p=.039)$ self-confidence ratings, supporting Greenfield's and Kasser's theories.

\section{Materialism}

In line with Sheldon's (2005) findings, materialism declined from freshman to senior year for both prerecession and recession cohort, suggesting normative declines in materialism during undergraduate years (Table 2 and 3, Figure 3).

Pairwise comparison revealed that the downward developmental trajectories of the two cohorts were significantly different from each other. Materialism declined significantly less for the recession cohort compared with the prerecession cohort $(p<.001)$, favoring Kasser's theory.

\section{First-Generation Status}

First-generation status was not a significant moderator of the association between year and values. It also did not moderate the association of year and cohort on values. That is, the 
normative value change during undergraduate years and the Great Recession's influence on the value development trajectories did not differ for students with vs. without parents with undergraduate education.

First-generation status was associated with lower intellectual self-confidence rating $(p<$ $.001)$, stronger motivation to help others $(p=.021)$, and higher valuation of the importance of being very well-off financially $(p<.001)$.

\section{Overall Discussion}

Overall, results from two studies highlight that the Great Recession is associated with increased communitarianism (supporting Greenfield) and increased materialism (supporting Kasser) among American undergraduate students. Our research contributes to the literature by illustrating that macro-level economic downturns are associated with population- and individuallevel value development of communitarianism and materialism.

\section{Communitarianism}

Although the Great Recession has been an adverse event, our findings suggest a promising future outlook by demonstrating that undergraduate students may have responded to the recent economic crisis by cultivating community mindsets. The recession may have catalyzed students' development of communitarianism by fostering collectivistic values and emphasizing one's relation with others and the society as an adaptive strategy for thriving together during a societal time of economic hardships (Greenfield, 2009). For instance, as students increase their awareness of societal issues (Arnett, 2004), they may become sensitized to recession's influences on the society. In turn, such awareness and lived experience as a generation of youth navigating the economic crisis may prompt students to take greater interest in others and the society, with an intent to ameliorate societal problems. 
Interestingly, recent generations of undergraduate students may particularly focus on institutional responsibilities when coming to value communitarianism in the face of recessions. Examining the general association of values with recessions 1966-2015, only the importance of helping others, but not the importance of participating in community action programs or becoming involved in programs to clean up the environment, was associated with recessions. Nonetheless, a focus on the Great Recession revealed that the importance of participating in community action programs and cleaning up the environment increased even more than did the importance of helping others during that most recent recession (Study 1). Furthermore, in Study 2, the Great Recession was associated with heightened increases from freshman to senior year for the importance of community action programs and cleaning up the environment, but not helping others. Students of the Great Recession era may especially value institutional efforts as a means to address societal issues, which has important implications for social policies and political climates. For example, valuation of institutional efforts may influence students' political leanings or lead them to increase their political involvements during election seasons.

\section{Materialism}

The results concerning materialism provide a strong support for Kasser's theory (2002a), which suggests that economic difficulties threaten people's security and orient them towards materialism that may seem to promise security in uncertain situations. Attending undergraduate institutions during the Great Recession may have caused young adults apprehension about making a successful transition into a labor market, given high unemployment rates and uncertain recovery prospects.

Increased materialism during the recession is concerning and should guide future research, given prior work showing the association of higher materialism with poorer wellbeing 
(Kasser, 2002b). Relatedly, it will be an important future research direction to examine young people's motivation for valuing materialistic achievements. For example, they may value financial success with a goal of achieving personal status, supporting their family, or giving back to their community. Different motivations for endorsing financial success may have varying implications for development and wellbeing.

\section{Positive Self-Views}

Students became increasingly positive about themselves with or without the Great Recession (Study 2), suggesting normative development of positive self-views during undergraduate years. However, the Great Recession may have impeded students' normative development of positive self-views; the rate of increase was smaller for the cohort who experienced the Great Recession during undergraduate years compared with the immediately preceding cohort who completed undergraduate education before the Great Recession. This pattern complements the population-level pattern revealed by Study 1: a small decline in freshmen's above-average social self-confidence ratings and a stability of intellectual selfconfidence ratings from the precession to recession period, in the context of historical and generational rises in young people's positive self-views (Twenge \& Campbell, 2008). Although future research is warranted, our findings hint that prior rises in positive self-views may have slowed during the Great Recession.

It is possible that students' concerns about their employment after undergraduate education, especially as they near graduation, slowed students' development of positive selfviews (Kasser, 2002a). Given that positive-self views may reflect an inflated sense of personal aptitude, results may also be interpreted as more realistic self-views during recessions. Inflated positive self-views may be less adaptive in times of economic difficulties when collectivistic 
values such as communitarianism gain importance and individualistic focus on the self may be discouraged (Greenfield, 2009).

\section{Normative Value Development during Undergraduate Years}

In addition to demonstrating value development associated with the Great Recession, our findings add to the limited literature on normative value development in young adulthood. Our findings bolster Sheldon's (2005) prior research showing increased positive self-views and declining materialism during undergraduate years. Yet contrary to the prior study, our findings demonstrate that communitarianism increase during undergraduate years.

Development of more communitarianism and positive self-views and less materialism over the course of undergraduate years may be attributed to a combination of maturation of young adulthood, obtainment of educational training, and increased social interactions. For instance, students may build intellectual and social self-confidence as they expand their social network and learn academic materials. Materialism may decline as seeking life meaning and purpose becomes important (Eccles, Templeton, Barber, \& Stone, 2003; Sheldon, 2005). Students may also develop a more realistic perception of financial achievement, leading to weaker endorsement of the personal importance of being financially "very well-off", instead focusing on realistically achievable financial goals (O’Connor \& Raile, 2015).

\section{Limitations and Future Directions}

Although we had national samples of four-year undergraduate students, many young adults do not attend four-year universities. In the U.S., most adolescents attend high school, but only about $40 \%$ of young adults enroll in four-year universities immediately following high school (National Center for Education Statistics, n.d.). As such, our participants comprised a privileged segment of the larger population of young adults in the society. Our results indicate 
that the Great Recession has shaped value development similarly for students with different socioeconomic backgrounds, but the recession's effects on young adults who entered the workforce instead of pursuing undergraduate education remain to be explored. Additionally, alternative methodologies, including qualitative research, would contribute to the literature; we relied on Likert-scale ratings on a limited number of items, and there could have been some ceiling effects. Future research should also investigate how value change during the recession may lead to behavioral changes, such as by examining voting behavior.

\section{Conclusions}

Contributing to the emerging literature on the Great Recession's influence on young people's value development, the present research offers theoretical and practical implications. As for the theoretical implications, findings in the study provide partial support for two competing theories hypothesizing how economic downturns shape people's values. Our findings bolster Greenfield's notion of increased communitarianism in times of less economic affluence, and challenges Kasser's idea that people devalue community feelings during economic hardships. On the other hand, our findings support Kasser's assertion that feelings of uncertainty generated during economic hardships may increase materialism; the same findings challenge Greenfield's idea that materialistic values are lower in times of relative economic deprivation. Lastly, our research adds support for both Greenfield's and Kasser's notions that the development of positive self-views may be hampered during recessions.

The coupled rise of communitarianism and materialism is noteworthy as it suggests that students are capable of increasing societal awareness and engaging in addressing societal issues, despite heightened concerns about materialistic uncertainties during economic crisis. The Great 
Recession's influence on undergraduate students' values has important implications for the society, as they are important shapers of future societal values, decisions, and policies. 


\section{References}

Arnett, J. J. (2004). Emerging adulthood. New York, NY: Oxford University Press.

Bianchi, E. C. (2015). Assessing the robustness of the relationship between entering adulthood in a recession and narcissism. Psychological Science, 26, 537-538. doi:10.1177/0956797614568157

Eccles, J., Templeton, J., Barber, B., \& Stone, M. (2003). Adolescence and emerging adulthood: The critical passage ways to adulthood. In M. H. Bornstein, L. Davidson, C. L. M. Keyes, \& K. A. Moore (Eds.), Well-being: Positive development across the life course (pp.383406). Mahwah, NJ: Lawrence Erlbaum Associates Publishers.

Gentile, B., Twenge, J. M., Freeman, E. C., \& Campbell, W. K. (2012). The effect of social networking websites on positive self-views: An experimental investigation. Computers in Human Behavior, 28, 1929-1933. doi:10.1016/j.chb.2012.05.012

Giuliano, P. \& Spilimbergo, A. (2014). Growing up in a Recession. Review of Economic Studies, 81(2), 787-817. doi:10.1093/restud/rdt040

Greenfield, P. M. (2009). Linking social change and developmental change: shifting pathways of human development. Developmental Psychology, 45, 401-418. doi:10.1037/a0014726

Grusky, D. B., Western, B., \& Wimer, C. C. (Eds.). (2011). The Great Recession. NY: Russell Sage.

Heine, S. J., Lehman, D. R., Markus, H. R., \& Kitayama, S. (1999). Is there a universal need for positive self-regard? Psychological Review, 106(4), 766-794.

Kasser, T. (2002a). Sketches for a self-determination theory of values. Handbook of selfdetermination research, 123-140.

Kasser, T. (2002b). The high price of materialism. Cambridge, MA: MIT press. 
Kasser, T., Ryan, R. M., Zax, M., \& Sameroff, A. J. (1995). The relations of maternal and social environments to late adolescents' materialistic and prosocial values. Developmental Psychology, 31(6), 907-914.

Markus H. R. \& Kitayama, S. (2010). Cultures and selves: A cycle of mutual constitution. Perspectives on Psychological Science, 5, 420-430. doi:10.1177/1745691610375557

National Center for Education Statistics (n.d.). Fast facts. Retrieved from https://nces.ed.gov/fastfacts/display.asp?id=51

O’Connor, A., \& Raile, A. N. (2015). Millennials' "Get a 'real job”": Exploring generational shifts in the colloquialism's characteristics and meanings. Management Communication Quarterly, 29, 276-290. doi:10.1177/0893318915580153

Park, H., Twenge, J. M. \& Greenfield, P. M. Social Psychological and Personality Science, 5, 310-318. doi: $10.1177 / 1948550613495419$

Piff, P. K., Kraus, M. W., Côté, S., Cheng, B. H., \& Keltner, D. (2010). Having less, giving more: the influence of social class on prosocial behavior. Journal of Personality and Social Psychology, 99(5), 771-784. doi:10.1037/a0020092

Schwartz, S. H. (1994). Are there universal aspects in the structure and contents of human values? Journal of Social Issues, 50(4), 19-45. doi:10.1111/j.1540-4560.1994.tb01196.x

Sheldon, K. M. (2005). Positive value change during college: Normative trends and individual differences. Journal of Research in Personality, 39, 209-223. doi:10.1016/j.jrp.2004.02.002

Stephens, N. M., Fryberg, S. A., Markus, H. R., Johnson, C. S., \& Covarrubias, R. (2012). Unseen disadvantage: how American universities' focus on independence undermines the academic performance of first-generation college students. Journal of Personality and 
Social Psychology, 102(6), 1178-1197. doi:10.1037/a0027143

Stewart, A. J., \& Healy, J. M. (1989). Linking individual development and social changes. American Psychologist, 44(1), 30-42. doi: 10.1037/0003-066X.44.1.30

Tönnies, F. (1957). Community and society (Gemeinschaft und Gesellschaft, C. P. Loomis, Ed. \& Trans.). East Lansing: Michigan State University Press.

Twenge, J. M. (2010). Time-lag study. In N. Salkind (Ed.), Encyclopedia of research design (pp. 1518-1520). Thousand Oaks, CA: SAGE Publications, Inc. doi:10.4135/9781412961288.n464

Twenge, J. M. \& Campbell, W. K. (2010). Birth cohort differences in the Monitoring the Future dataset and elsewhere: Further evidence for Generation Me-Commentary on Trzesniewski \& Donnellan (2010). Perspectives on Psychological Science, 5(1), 81-88. doi:10.1177/1745691609357015

Twenge, J. M. \& Campbell, W. K. (2008). Increases in positive self-views among high school students: Birth-cohort changes in anticipated performance, self-satisfaction, self-liking, and self-competence. Psychological Science, 19, 1082-1086. doi:10.1111/j.14679280.2008.02204.x

Vohs, K. D., Mead, N. L., \& Goode, M. R. (2006). The psychological consequences of money. Science, 314(5802), 1154-1156. doi:10.1126/science.1132491 
Table 1

Aggregate-Level Freshmen's Values, Study 1

\begin{tabular}{|c|c|c|c|c|c|c|}
\hline \multirow[b]{4}{*}{ Variable } & \multirow{4}{*}{$\begin{array}{l}\text { Prerecession } \\
\qquad \begin{array}{c}(2004-06) \\
\%\end{array}\end{array}$} & \multirow{4}{*}{$\begin{array}{c}\text { Recession } \\
(2008-10) \\
\\
\%\end{array}$} & \multirow{3}{*}{\multicolumn{2}{|c|}{$\begin{array}{c}\text { Prerecession } \\
\text { vs. } \\
\text { Recession }\end{array}$}} & \multirow{3}{*}{\multicolumn{2}{|c|}{$\begin{array}{l}\text { Correlations with } \\
\text { unemployment } \\
\text { rates (1966-2015) }\end{array}$}} \\
\hline & & & & & & \\
\hline & & & & & & \\
\hline & & & $d$ & $p$ & $r(d f)$ & $p$ \\
\hline \multicolumn{7}{|l|}{ Communitarianism } \\
\hline Importance of helping others ${ }^{1}$ & 65.06 & 69.32 & .09 & $<.001$ & $.32(48)$ & .028 \\
\hline Importance of community action programs ${ }^{1}$ & 24.62 & 29.83 & .12 & $<.001$ & $.27(43)$ & .072 \\
\hline Importance of cleaning up the environment ${ }^{1}$ & 19.94 & 27.97 & .19 & $<.001$ & $.06(43)$ & 689 \\
\hline \multicolumn{7}{|l|}{ Positive self-views } \\
\hline Above-average social self-confidence ${ }^{2}$ & 52.70 & 51.82 & -.02 & $<.001$ & $.09(34)$ & .521 \\
\hline Above-average intellectual self-confidence ${ }^{2}$ & 59.90 & 60.11 & .00 & .072 & $.01(34)$ & .942 \\
\hline \multicolumn{7}{|l|}{ Materialism } \\
\hline Important to be very well-off financially ${ }^{1}$ & 73.82 & 77.41 & .08 & $<.001$ & $.36(47)$ & .010 \\
\hline
\end{tabular}


Table 2

Individual-Level Longitudinal Prerecession and Recession Cohort Students' Values in Freshman and Senior Year, Study 2

\begin{tabular}{|c|c|c|c|c|c|}
\hline \multirow{3}{*}{ Variable } & \multicolumn{3}{|c|}{ Prerecession (2002-06) } & \multicolumn{2}{|c|}{ Recession (2006-10) } \\
\hline & Range & Freshman & Senior & Freshman & Senior \\
\hline & & $M(S D)$ & $M(S D)$ & $M(S D)$ & $M(S D)$ \\
\hline \multicolumn{6}{|l|}{ Communitarianism } \\
\hline Importance of helping others ${ }^{1}$ & $1-4$ & $2.88(.78)$ & $3.06(.79)$ & $2.94(.81)$ & $3.11(.76)$ \\
\hline Importance of community action programs ${ }^{1}$ & $1-4$ & $2.04(.81)$ & $2.18(.89)$ & $2.14(.86)$ & $2.35(.88)$ \\
\hline Importance of cleaning up the environment ${ }^{1}$ & $1-4$ & $1.82(.76)$ & $2.01(.84)$ & $1.95(.84)$ & $2.22(.87)$ \\
\hline \multicolumn{6}{|l|}{ Positive self-views } \\
\hline Above-average social self-confidence ${ }^{2}$ & $1-5$ & $3.70(.80)$ & $3.84(.79)$ & $3.74(.80)$ & $3.86(.80)$ \\
\hline Above-average intellectual self-confidence ${ }^{2}$ & $1-5$ & $3.42(.89)$ & $3.62(.88)$ & $3.49(.88)$ & $3.63(.90)$ \\
\hline \multicolumn{6}{|l|}{ Materialism } \\
\hline Important to be very well-off financially ${ }^{1}$ & $1-4$ & $2.82(.90)$ & $2.65(.92)$ & $2.87(.90)$ & $2.76(.89)$ \\
\hline
\end{tabular}


Table 3

Multiple Regression Models Predicting Prerecession and Recession Cohort Students' Values, Study 2

\begin{tabular}{|c|c|c|c|c|c|c|c|c|c|c|c|c|}
\hline \multirow[b]{4}{*}{ Variable } & \multicolumn{6}{|c|}{ Communitarianism } & \multicolumn{4}{|c|}{ Positive self-views } & \multicolumn{2}{|c|}{ Materialism } \\
\hline & \multirow{2}{*}{\multicolumn{2}{|c|}{ Help others }} & \multirow{2}{*}{\multicolumn{2}{|c|}{$\begin{array}{c}\text { Community } \\
\text { action program }\end{array}$}} & \multirow{2}{*}{\multicolumn{2}{|c|}{$\begin{array}{l}\text { Clean up the } \\
\text { environment }\end{array}$}} & \multirow{2}{*}{\multicolumn{2}{|c|}{$\begin{array}{l}\text { Social self- } \\
\text { confidence }\end{array}$}} & \multirow{2}{*}{\multicolumn{2}{|c|}{$\begin{array}{l}\text { Intellectual self- } \\
\text { confidence }\end{array}$}} & \multirow{2}{*}{\multicolumn{2}{|c|}{$\begin{array}{l}\text { Be very well- } \\
\text { off financially }\end{array}$}} \\
\hline & & & & & & & & & & & & \\
\hline & $b$ & $S E$ & $b$ & $S E$ & $b$ & $S E$ & $b$ & $S E$ & $b$ & $S E$ & $b$ & $S E$ \\
\hline Intercept & $2.73^{* * *}$ & .01 & $1.92^{* * *}$ & .01 & $1.80^{* * *}$ & .01 & $3.52^{* * *}$ & .01 & $3.92^{* * *}$ & .01 & $2.87^{* * *}$ & .01 \\
\hline Age & $.02^{*}$ & .01 & .01 & .01 & .00 & .01 & .01 & .01 & -.01 & .01 & $-.08^{* * *}$ & .01 \\
\hline Sex & $.21^{* * * *}$ & .01 & $.20^{* * * *}$ & .01 & $.02^{* *}$ & .01 & $-.15^{* * *}$ & .01 & $-.32^{* * *}$ & .01 & $-.15^{* * *}$ & .01 \\
\hline Year & $.19^{* * *}$ & .01 & $.14^{* * *}$ & .01 & $.20^{* * *}$ & .01 & $.20^{* * *}$ & .01 & $.15^{* * *}$ & .01 & $-.16^{* * *}$ & .01 \\
\hline Cohort & $.06^{* * * *}$ & .01 & $.09^{* * * *}$ & .01 & $.13^{* * *}$ & .01 & $.07^{* * *}$ & .01 & $.03^{* *}$ & .01 & $.05^{* * *}$ & .01 \\
\hline First generation & $.04^{*}$ & .02 & -.02 & .02 & .01 & .02 & .01 & .02 & $-.06^{* * *}$ & .02 & $.19^{* * *}$ & .02 \\
\hline Year * First gen & -.03 & .02 & -.01 & .02 & -.02 & .02 & -.01 & .03 & -.01 & .02 & -.02 & .03 \\
\hline Cohort $*$ First gen & .03 & .02 & .04 & .03 & .00 & .02 & -.03 & .03 & .00 & .02 & .02 & .03 \\
\hline Year * Cohort & -.02 & .02 & $.07^{* * *}$ & .02 & $.07^{* * *}$ & .02 & $-.07^{* * *}$ & .02 & $-.03^{*}$ & .01 & $.07^{* * *}$ & .02 \\
\hline Year $*$ Cohort $*$ First gen & .00 & .03 & -.01 & .04 & .02 & .03 & .05 & .04 & .01 & .03 & -.05 & .04 \\
\hline
\end{tabular}


Note. Sex: $0=$ male, $1=$ female; first generation: $0=$ continuing-generation, $1=$ first-generation; cohort: $0=$ prerecession, $1=$ recession; year: 1 = freshman, 2 = senior. 

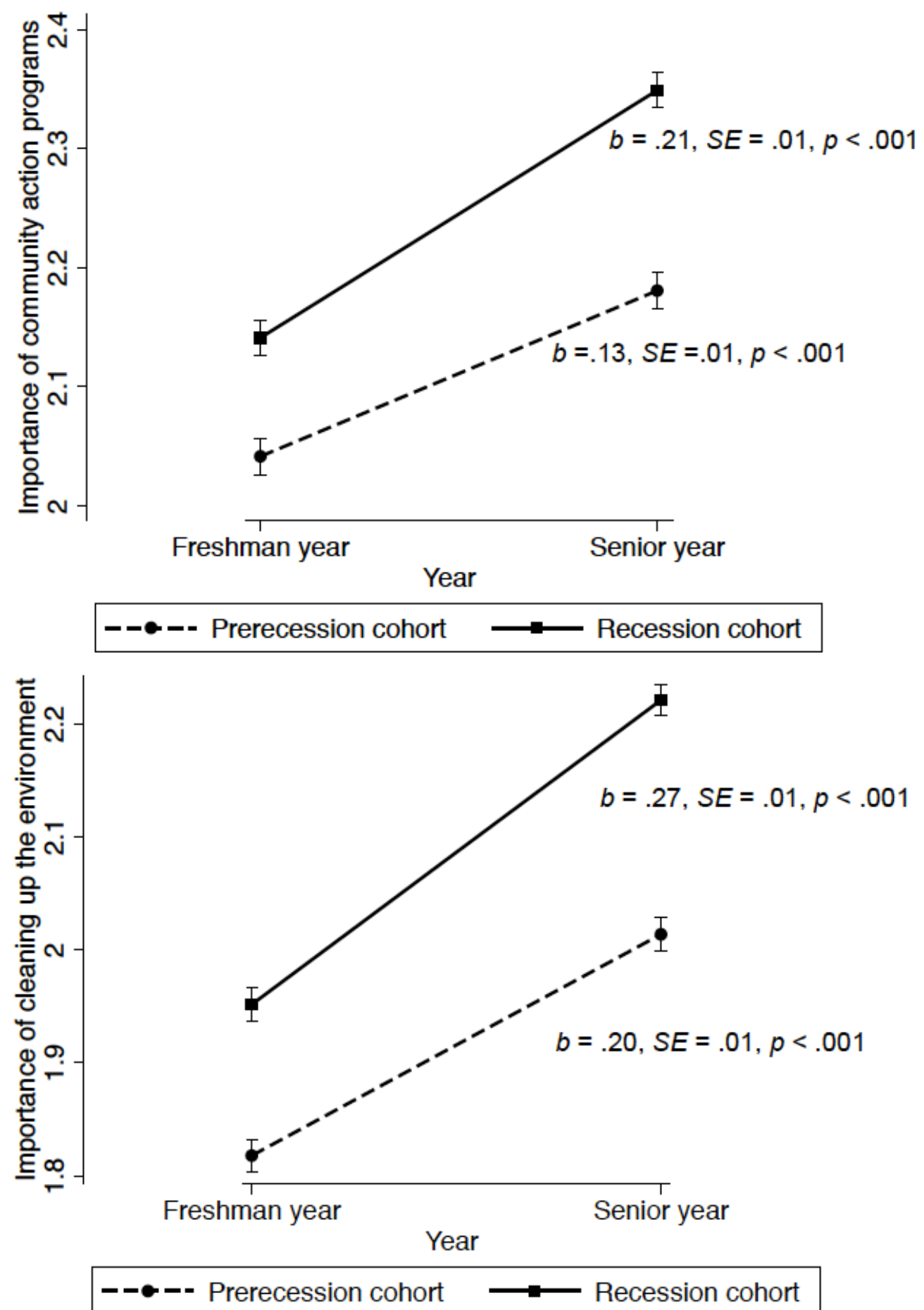

Figure 1. Development of communitarianism 


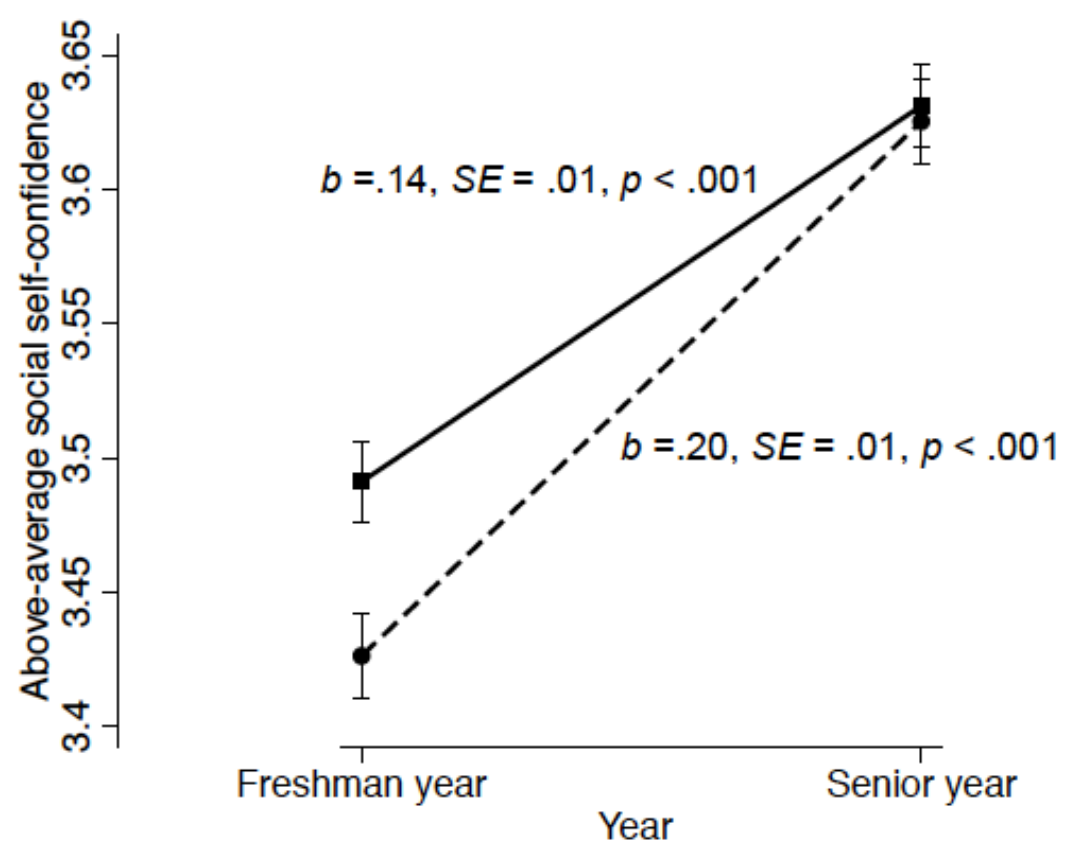

-ー๑-- Prerecession cohort $\longrightarrow$ Recession cohort

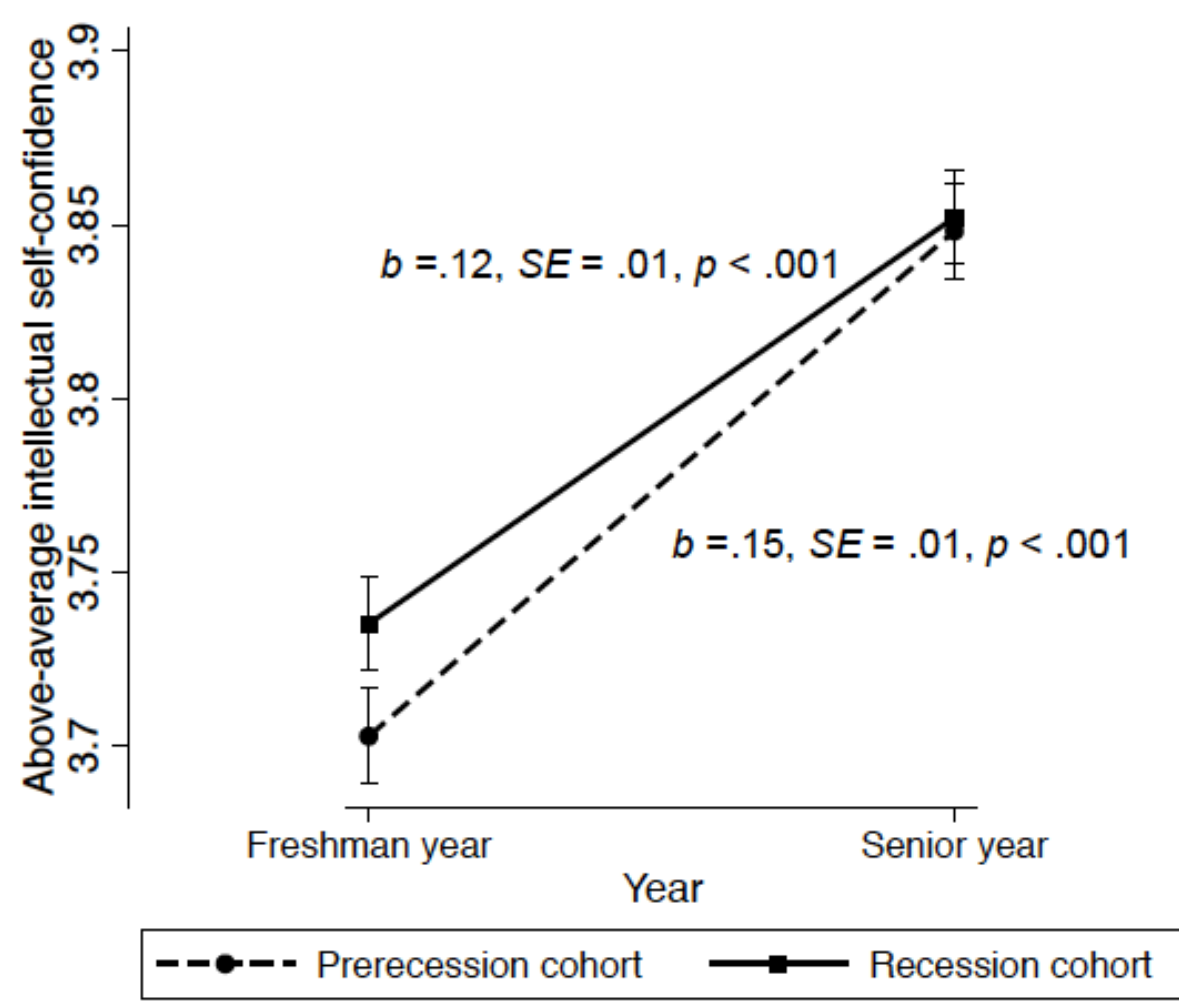

Figure 2. Development of positive self-views 


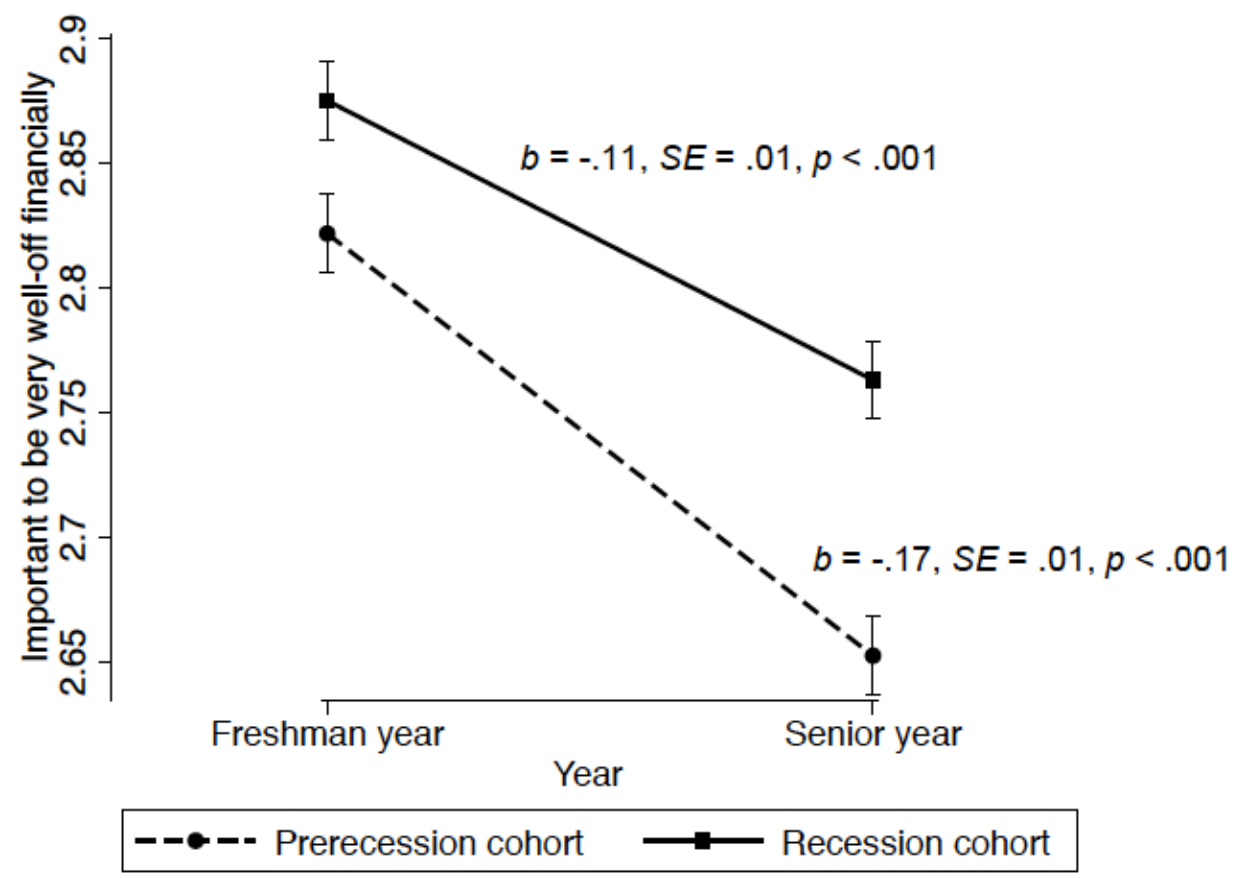

Figure 3. Development of materialism 